\title{
Genetic Divergence Studies in Subspecies of Oryza sativa L.
}

\author{
R. Sangeetha, R. Saraswathi", K. Amudha and G. Senthil Kumar \\ Department of Rice, Centre for Plant Breeding and Genetics, Tamil Nadu Agricultural \\ University, Coimbatore - 03, Tamil Nadu, India \\ *Corresponding author
}

\section{Keywords}

Rice, indica, Tropical japonica, D2 statistics, Molecular diversity

Article Info

Accepted:

07 June 2019 Available Online: 10 July 2019

\section{A B S T R A C T}

An experiment was carried out to study the divergence among twenty four rice genotypes (14 indica and 10 japonica lines) for 15 agro-morphological traits using $\mathrm{D}^{2}$ statistics and at molecular level using 114SSR markers. The cluster analysis using Mahalonobis' $\mathrm{D}^{2}$ statistics classified the genotypes into five clusters. The cluster IV was the largest with seven indica and three tropical japonica types. The second largest cluster (V) accommodated four tropical japonica and two indica genotypes. The intra cluster distance ranged from 1.077 to 8.299 and it showed a gradual increase from cluster I to cluster V. Cluster III with four genotypes showed the highest inter cluster distance with cluster I (14.312), followed by cluster II (12.032) and cluster IV (11.734). Cluster II with AC 38479 and IR 64 showed the highest mean values for five traits viz., panicle length, number of primary branches panicle ${ }^{-1}$, number of secondary branches panicle $^{-1}$, filled grains panicle ${ }^{-1}$ and single plant yield and the lowest mean values for hundred grain weight, kernel length, kernel breadth and kernel thickness which are desirable. The kernel traits viz., kernel L/B ratio (35.14\%), 100 grain weight (25.73\%), kernel thickness (14.13\%) and kernel breadth (12.31\%) alone contributed for $87.31 \%$ of the total genetic divergence. In molecular diversity analysis, 69 SSR markers were detected to be polymorphic out of 114 markers. In total, 216 alleles were detected and the number of alleles amplified ranged between two to seven. The average number of alleles obtained was 3.13. The Polymorphism Information Content (PIC) which reflects the allelic diversity varied from 0.08 (RM2) to 0.81(RM3317) and its average was 0.5 . The dendrogram based on the UPGMA classified the 24 genotypes into four major distinguishable clusters with two sub clusters for cluster I. The Jaccard's dissimilarity index was lowest (0.34) between CB 16144 and CB 15138; highest (0.89) between CB 16174 and Pato as well as between CB 16174 and AC 38476. It is concluded that in both methods, some distinct genotypes in each group were accommodated in the same cluster without separation. Also, no distinct clusters were formed for each of the two sub groups indica and tropical japonica separately but the genotypes of both the groups were spread over all clusters indicating sufficient genetic diversity within the groups which can be utilized in selecting parents for hybridization program. 


\section{Introduction}

Being the staple food crop for more than half of the global populations, the increase in the rice production after Green revolution, helped many countries to escape starvation. The world rice production was $516.36 \mathrm{mt}$ (milled rice) in 2018-19 from 165.15 million ha area and in India, it was 115.6 million tonnes produced from about 43.37 million ha area (FAO-AMIS 2018-19).

An alarming increase in the human population creates a high demand for rice production in future but the major challenge is the plateauing effect in the growth rate due to the narrowing down of the genetic constitution as a result of directional selection.

Understanding the genetic relationships among breeding materials could be an invaluable aid in crop improvement strategies. A large amount of genetic diversity has been eroded both in indica and japonica subspecies during domestication of Asian rice (Ndjiondjop et al., 2010, Kumar et al., 2014). Moreover, in recent years, breeders have the practice of selecting elite Asian rice genotypes (indica) as parents in breeding programmes because of its widespread adoption but the resultant improved varieties have decreased the genetic diversity of rice gene pool.

The effect is much pronounced in crosses between closely related parents in their pedigree, repetitive use of very few mega varieties as one of the parents in crossing programs and trait improvement for selected stresses by marker assisted backcross breeding in the mega varieties. Such prolonged and widespread use of single/few genotypes erodes new alleles from the population which might be the major contributing factor for the increased vulnerability to various biotic/abiotic stresses and importantly the yield plateauing witnessed in rice production.
To overcome these challenges, introduction of new favourable alleles from genetic material of closely related species within the genus Oryza is considered a promising approach. Hence, the present study was aimed at evaluating the genetic and molecular divergence among 24 rice genotypes belonging to indica and tropical japonica subspecies which will be helpful in differentiating the genotypes with greater uniqueness that can be used in the hybridization programmes in future.

\section{Materials and Methods}

\section{Plant materials}

A set of 24 rice genotypes comprising of fourteen indica types and ten tropical japonica types as listed in Table 1 were grown at Paddy Breeding Station, Department of Rice, Centre for Plant Breeding and Genetics (CPBG), Tamil Nadu Agricultural University, Coimbatore in Randomized Block Design (RBD) with three replications during June 2018. All the indica types except IR 64 were bred at TNAU, Coimbatore. The tropical japonica types bred elsewhere are maintained in germplasm collection of Paddy Breeding station, TNAU.

\section{Observations and analysis of agro- morphological traits}

Observations were recorded on single plant basis except days to $50 \%$ flowering on five randomly tagged plants per genotype in each replication for 15 quantitative traits namely, days to fifty per cent flowering, plant height $(\mathrm{cm})$, productive tillers (nos.), panicle length $(\mathrm{cm})$, number of primary branches panicle $^{-1}$, number of secondary branches panicle $^{-1}$, filled grains panicle ${ }^{-1}$ (nos.), panicle weight (g), spikelet fertility (\%), 100 grain weight $(\mathrm{g})$, single plant yield $(\mathrm{g})$, kernel length $(\mathrm{mm})$, kernel breadth $(\mathrm{mm})$, kernel thickness 
(mm) and kernel length- breadth ratio. The data was subjected to Mahalanobis' $D^{2}$ statistics (Mahalanobis, 1928). The analysis was performed using GENRES software and the $\mathrm{D}^{2}$ values were used to obtain the cluster based on the method suggested by Tocher (Radhakrishna Rao, 1952). The inter and intra cluster distances were estimated along with the per cent contribution of each quantitative trait for divergence.

\section{Molecular marker analysis}

Genomic DNA of 24 genotypes was extracted from 20-day old leaves using Cetyl Trimethyl Ammonium Bromide (CTAB) method. The DNA concentration was assessed using NanoDrop Spectrophotometer and it was diluted to $40 \mathrm{ng}$ and stored at $-20^{\circ} \mathrm{C}$.A total of 114 Simple Sequence Repeat (SSR) markers spanning the twelve chromosomes of rice were selected from the Gramene database; http://www.gramene.org/microsat/ssr.html

which spreads across all 12 chromosomes of rice. The PCR amplification was performed in Bio-Rad (MyCycler thermal cycler). Total PCR reaction was optimized to be $10 \mu \mathrm{l}$ and this included $2.0 \mu \mathrm{l}$ of about 40ng DNA template, $4.0 \mu$ l PCR master mix (SmartPrime red), $1 \mu \mathrm{l}$ of each primer (forward and reverse primer), and $3.0 \mu$ l nuclease free water. The temperature cycle for amplification was programmed as initial denaturation at $95^{\circ} \mathrm{C}$ for $4 \mathrm{~min}$, denaturation at $94^{\circ} \mathrm{C}$ for $45 \mathrm{~s}$, annealing at $55^{\circ} \mathrm{C}$ for $30 \mathrm{~s}$, extension at $72^{\circ} \mathrm{C}$ for $1 \mathrm{~min}$ for 35 cycles followed by final extension at $72^{\circ} \mathrm{C}$ for $5 \mathrm{~min}$ and $4^{\circ} \mathrm{C}$ for cooling. But the annealing temperature was adjusted based on the specific requirements of different primer and their CG content. The PCR products were separated through electrophoresis employing 3.0 per cent agarose gel in $1 \mathrm{X}$ TBE buffer at $110 \mathrm{~V}$ for $2 \mathrm{~h} 30 \mathrm{~min}$ along with $100 \mathrm{bp}$ DNA ladder. The documentation of the Ethidium bromide stained fragments was done by UviTechFireReader.
The migration distance of amplified fragments was determined by relative comparison with the molecular weight of the 100 base pair DNA ladder. Clear and discrete amplified bands were scored for the presence (1) or absence (0) of the corresponding bands among the genotypes. The data were recorded as a binary matrix and analysis was performed in DAR win 6. Coefficient of dissimilarity was calculated by using Jaccard's coefficient and cluster analysis was performed by agglomerative technique using the UPGMA (Un-weighted Pair Group Method with Arithmetic mean) method. Relationships among rice genotypes were graphically represented in the form of dendrogram.

The discriminatory power of a particular locus or loci given by Polymorphic information content (PIC)was estimated by considering the number of alleles and the relative frequency of their occurrence using the formula given by Smith et al., (1997).

$\mathrm{PIC}=1-\Sigma \mathrm{p}_{\mathrm{i}}^{2}$

Where, ' $p_{i}$ ' is the frequency of the $i^{\text {th }}$ allele.

\section{Results and Discussion}

\section{Genetic diversity for agro-morphological traits}

Analysis of variance showed significant differences among the genotypes for all the fifteen traits studied which suggests the existence of considerable variation among them. The pattern of grouping of 24 genotypes into five clusters (Table 2) proved the existence of significant amount of diversity. A survey of recent literatures pertaining to our study revealed the formation of five clusters in the investigations by Siddique et al., (2013), (Kumar et al., 2014) involving 40 and 134 genotypes for 14 and 16 traits. Chakma et al., (2012), Ranjith et al., (2018), Singh et al., 
(2018) and Tiruneh et al., (2019) obtained six clusters with around same number of genotypes viz., 39, 30, 30 and 36 for 12, 12, 14 and 15 traits respectively. In a study with 51 genotypes, Palaniraja and Anbuselvam (2010) reported as many as 15 clusters for just seven traits.

Cluster IV was the largest with10 genotypes of which seven belonged to the indica group. In cluster V, four genotypes viz., Iguapecateto, Nira, Palwan and Pato were tropical japonica and the rest were indica. Among four genotypes of cluster III, two each were indica and tropical japonica. Two indica types viz., CB 16168 and Paiyur 1 were grouped in cluster II; IR 64 and tropical japonica AC 38479 were grouped in cluster I. Thus it could be noticed that no distinctive clusters were formed for each of the two sub groups indica and tropical japonica but the genotypes of both the groups were spread over all clusters indicating sufficient genetic diversity within the groups. According to Shanmugam and Sree Rangasamy (1982) the grouping of genetic material of same geographical origin into varied clusters indicated the broad genetic base of genotypes belonging to that origin. It could be observed that three indica genotypes viz., CB 16166, CB 16168 and CB 16170 derived from same cross ADT 49/Wag wag were grouped into three different clusters viz., IV, II and V indicating their wide variability. So also, CB 16174 derived from ADT 49/WGL 14 fell into separate cluster III along with IR 64. Similar results of genotypes belonging to a common origin but spreading across different clusters were reported by Shanmugasundaram et al., (2000) and Beevi and Venkatesan (2015).

\section{Intra and inter cluster distances}

The intra cluster distance ranged from 1.077 to 8.299 and it showed a gradual increase from cluster I to cluster V (Table 3) in this experiment. Cluster III with four genotypes showed the highest inter cluster distance with cluster I (14.312), followed by cluster II (12.032) and cluster IV (11.734).

In studies with similar group of clusters (five), the utmost distance was reported between III and II Siddique et al., (2013) and between IV and V Kumar et al., (2014). Their genetic distances were 36.45 and 22.36 respectively. In six clusters Chakma et al., (2012) reported the highest genetic distance of 15.84 between clusters II and III. So also, Baradhan and Thangavel (2011) obtained a genetic distance of 13.2 between II and VI. Low genetic distances of 9.81 (Cluster V and IX) was observed in studies by Chandramohan et al., (2016) among seven clusters for 44 genotypes. Genetic distance as high as 18054 (VI and VII) in nine clusters for 12 traits in 70 genotypes was reported by Ovung et al., (2012). In intra cluster distance, values of 4.05 (IV), 4.685 (III), 8.04 (I), 9.54 (VII) and 12.19 (IV) close to the present study has been published by Chandramohan et al., (2016), Singh et al., (2018), Baradhan and Thangavel (2011),Guru et al., (2017) and Kumar et al., (2014). Extreme values of 0 (Bomit et al., 2018) and 2907 Ovung et al., (2012) have also been encountered in similar investigations on genetic diversity.

\section{Cluster mean value for biometrical traits}

The cluster mean values for fifteen biometrical traits are depicted in Table 4. Cluster II with AC 38479 and IR 64 showed the highest mean values for five traits viz., panicle length $(26.32 \mathrm{~cm})$, number of primary branches panicle $^{-1}$ (16.33), number of secondary branches panicle $^{-1}$ (41.67), filled grains panicle $^{-1}$ (173.33) and single plant yield $(37.17 \mathrm{~g})$ and the lowest mean values for hundred grain weight $(1.513 \mathrm{~g})$, kernel length $(4.86 \mathrm{~mm})$, kernel breadth $(1.83 \mathrm{~mm})$ and kernel thickness $(1.38 \mathrm{~mm})$ which are desirable. 


\begin{tabular}{|c|c|c|c|c|c|}
\hline \multicolumn{5}{|c|}{ Table.1a Description of the 24 rice cultivars evaluated for genetic diversity and } \\
molecular diversity analysis \\
\hline $\begin{array}{c}\text { S. } \\
\text { No. }\end{array}$ & Genotype & $\begin{array}{c}\text { Genotype } \\
\text { group }\end{array}$ & S. No. & Genotype & Genotype group \\
\hline $\mathbf{1}$ & CB 87 R & indica & $\mathbf{1 3}$ & Paiyur 1 & indica \\
\hline $\mathbf{2}$ & CB $174 \mathrm{R}$ & indica & $\mathbf{1 4}$ & IR 64 & indica \\
\hline $\mathbf{3}$ & CB 12132 & indica & $\mathbf{1 5}$ & AC 38471 & tropical japonica \\
\hline $\mathbf{4}$ & CB 15120 & indica & $\mathbf{1 6}$ & AC 38476 & tropical japonica \\
\hline $\mathbf{5}$ & CB 15127 & indica & $\mathbf{1 7}$ & AC 38479 & tropical japonica \\
\hline $\mathbf{6}$ & CB 15138 & indica & $\mathbf{1 8}$ & Azucena & tropical japonica \\
\hline $\mathbf{7}$ & CB 16139 & indica & $\mathbf{1 9}$ & Bluebonnet & tropical japonica \\
\hline $\mathbf{8}$ & CB 16144 & indica & $\mathbf{2 0}$ & Iguapecateto & tropical japonica \\
\hline $\mathbf{9}$ & CB 16166 & indica & $\mathbf{2 1}$ & Khao do ngoi & tropical japonica \\
\hline $\mathbf{1 0}$ & CB 16168 & indica & $\mathbf{2 2}$ & Nira & japonica \\
\hline $\mathbf{1 1}$ & CB 16170 & indica & $\mathbf{2 3}$ & Palawan & tropical japonica \\
\hline $\mathbf{1 2}$ & CB 16174 & indica & $\mathbf{2 4}$ & Pato & tropical japonica \\
\hline
\end{tabular}

\begin{tabular}{|c|l|l|}
\hline \multicolumn{3}{|c|}{ Table.1b Pedigree details of the genotypes used in the genetic diversity study } \\
\hline S. No. & \multicolumn{1}{|c|}{ Genotype } & \multicolumn{1}{c|}{ Pedigree details } \\
\hline $\mathbf{1}$ & CB 12132 & C30101 x CB05501 \\
\hline $\mathbf{2}$ & CB 15120 & IR20 x BPT5204 \\
\hline $\mathbf{3}$ & CB 15127 & ADT (R)49 x CB04044 \\
\hline $\mathbf{4}$ & CB 15138 & CB09153 x BG358 \\
\hline $\mathbf{5}$ & CB 16139 & IR20 x BPT5204 \\
\hline $\mathbf{6}$ & CB 16144 & IR20 x JGC384 \\
\hline $\mathbf{7}$ & CB 16166 & ADT (R)49 x wag wag \\
\hline $\mathbf{8}$ & CB 16174 & ADT (R)49 x WGL14 \\
\hline $\mathbf{9}$ & CB 16170 & ADT (R)49 x wag wag \\
\hline $\mathbf{1 0}$ & CB 16168 & ADT (R)49 x wag wag \\
\hline $\mathbf{1 1}$ & Paiyur 1 & IR 1721- 14/IR 1330-33-2 \\
\hline
\end{tabular}

\begin{tabular}{|c|c|l|}
\hline \multicolumn{3}{|c|}{ Table.2 Constitution of $\mathbf{D}^{2}$ clusters of 24 genotypes of rice } \\
\hline Cluster & $\begin{array}{c}\text { Number of } \\
\text { genotypes }\end{array}$ & \multicolumn{1}{|c|}{ Name of the genotype } \\
\hline I & 2 & AC38479, IR 64 \\
\hline II & 2 & CB 16168, Paiyur 1 \\
\hline III & 4 & AC 38471, AC 38476, CB 15127, CB 174R \\
\hline IV & 10 & $\begin{array}{l}\text { Azucena, Bluebonnet, CB 87R, CB 12132, CB 15120, CB } \\
\text { 15138, CB 16139, CB 16144, CB 16166, Khao do ngoi }\end{array}$ \\
\hline V & 6 & CB 16170, CB 16174, Iguapecateto, Nira, Palwan, Pato \\
\hline
\end{tabular}




\begin{tabular}{|c|c|c|c|c|c|}
\hline \multicolumn{6}{|c|}{ Table.3 Average intra-(in bold) and inter-cluster $\mathrm{D}^{2}$ distances } \\
\hline & I & II & III & IV & V \\
\hline I & 1.077 & 6.241 & 14.312 & 7.009 & 10.642 \\
\hline II & & 1.212 & 12.032 & 6.077 & 8.578 \\
\hline III & & & 5.424 & 11.734 & 8.969 \\
\hline IV & & & & 7.544 & 8.941 \\
\hline V & & & & & 8.299 \\
\hline
\end{tabular}

\begin{tabular}{|c|c|c|c|c|c|}
\hline \multicolumn{6}{|c|}{ Table.4 Cluster mean values for fifteen ago-morphological traits in rice } \\
\hline \multirow[t]{2}{*}{ CHARACTER } & \multicolumn{5}{|c|}{ CLUSTERS } \\
\hline & I & II & III & IV & V \\
\hline DFF & 111.167 & 100 & 101 & 105.333 & 98.944 \\
\hline PHT (cm) & 110.1 & 124.717 & 101.3 & 113.563 & 124.178 \\
\hline PTL & 13.5 & 15.667 & 14.583 & 16.767 & 13.611 \\
\hline PL (cm) & 26.317 & 23.55 & 22.1 & 23.947 & 23.261 \\
\hline PB & 16.333 & 10 & 10.333 & 12.1 & 11.056 \\
\hline SB & 41.667 & 30.5 & 25.833 & 35.367 & 34.444 \\
\hline FG & 173.333 & 171 & 90.667 & 151 & 126.556 \\
\hline PW (g) & 3.123 & 3.94 & 2.233 & 3.024 & 2.663 \\
\hline SF & 81.753 & 85.237 & 81.858 & 82.889 & 80.962 \\
\hline HGW (g) & 1.513 & 1.81 & 2.98 & 1.789 & 2.228 \\
\hline SPY $(g)$ & 37.167 & 35.758 & 27.509 & 34.931 & 37.342 \\
\hline KL & 4.86 & 5.555 & 5.93 & 5.251 & 5.929 \\
\hline KB & 1.832 & 2.078 & 2.596 & 2.057 & 2.217 \\
\hline KT & 1.378 & 1.492 & 1.79 & 1.498 & 1.583 \\
\hline LBR & 2.655 & 2.753 & 2.301 & 2.597 & 2.732 \\
\hline \multicolumn{6}{|c|}{$\begin{array}{l}\text { DFF-Days to heading, PHT-Plant height (cm), PTL-Productive tillers (No.), PL-Panicle length (cm), PB- } \\
\text { Primary branches / panicle (No.), SB-Secondary branches/ panicle (No.), FG-Number of filled grains } \\
\text { /panicle, PW-Panicle weight (g), SF- Spikelet fertility (\%), HGW-100 grain weight (g), SPY-Single plant } \\
\text { yield (g), KL-Kernel length (mm), KB-Kernel breadth (mm), KT-Kernel thickness (mm), LBR-L/B ratio }\end{array}$} \\
\hline
\end{tabular}

\begin{tabular}{|c|l|c|}
\hline \multicolumn{3}{|c|}{ Table.5 Contribution of each character to divergence } \\
\hline Sl. No & \multicolumn{1}{|c|}{ Character } & Contribution to divergence (per cent) \\
\hline $\mathbf{1}$ & Days to fifty per cent flowering & 0 \\
\hline $\mathbf{2}$ & Plant height (cm) & 0 \\
\hline $\mathbf{3}$ & Productive tillers (No.) & 0 \\
\hline $\mathbf{4}$ & Panicle length (cm) & 3.6232 \\
\hline $\mathbf{5}$ & Primary branches panicle ${ }^{-1}$ (No.) & 0.7246 \\
\hline $\mathbf{6}$ & Secondary branches panicle ${ }^{-1}$ (No.) & 0 \\
\hline $\mathbf{7}$ & Number of filled grains /panicle & 0.3623 \\
\hline $\mathbf{8}$ & Panicle weight (g) & 2.5362 \\
\hline $\mathbf{9}$ & Spikelet fertility $(\%)$ & 2.8986 \\
\hline $\mathbf{1 0}$ & 100 grain weight $(\mathrm{g})$ & 25.7246 \\
\hline $\mathbf{1 1}$ & Single plant yield (g) & 2.1739 \\
\hline $\mathbf{1 2}$ & Kernel length $(\mathrm{mm})$ & 0.3623 \\
\hline $\mathbf{1 3}$ & Kernel breadth $(\mathrm{mm})$ & 12.3188 \\
\hline $\mathbf{1 4}$ & Kernel thickness $(\mathrm{mm})$ & 14.1304 \\
\hline $\mathbf{1 5}$ & L/B ratio & 35.1449 \\
\hline & TOTAL & 100 \\
\hline
\end{tabular}


Int.J.Curr.Microbiol.App.Sci (2019) 8(7): 834-845

Table.6 Polymorphic SSR primers used for diversity analysis in rice genotypes and their polymorphism level

\begin{tabular}{|c|c|c|c|c|c|c|}
\hline S. No. & Marker & Chromosome & Annealing Temperature & $\begin{array}{l}\text { Expected Product } \\
\text { Size (bp) }\end{array}$ & PIC Value & Number of Alleles \\
\hline 1 & RM2 & 7 & 55 & 150 & 0.81 & 6 \\
\hline 2 & RM18 & 7 & 55 & 157 & 0.538 & 3 \\
\hline 4 & RM107 & 9 & 67 & 189 & 0.455 & 3 \\
\hline 5 & RM118 & 7 & 67 & 156 & 0.552 & 3 \\
\hline 6 & RM152 & 8 & 55 & 151 & 0.559 & 3 \\
\hline 7 & RM154 & 2 & 61 & 183 & 0.635 & 3 \\
\hline 9 & RM167 & 11 & 55 & 128 & 0.686 & 5 \\
\hline 10 & RM169 & 5 & 67 & 167 & 0.601 & 3 \\
\hline 11 & RM190 & 6 & 55 & 124 & 0.635 & 4 \\
\hline 12 & RM195 & 8 & 61 & 311 & 0.5 & 2 \\
\hline 13 & RM204 & 6 & 55 & 169 & 0.403 & 3 \\
\hline 14 & RM223 & 8 & 55 & 165 & 0.153 & 2 \\
\hline 15 & RM224 & 11 & 55 & 157 & 0.469 & 2 \\
\hline 16 & RM231 & 3 & 55 & 182 & 0.491 & 2 \\
\hline 17 & RM232 & 3 & 55 & 158 & 0.488 & 2 \\
\hline 20 & RM251 & 3 & 55 & 147 & 0.469 & 2 \\
\hline 21 & RM256 & 8 & 55 & 127 & 0.153 & 2 \\
\hline 22 & RM273 & 4 & 55 & 207 & 0.58 & 4 \\
\hline 23 & RM276 & 3 & 55 & 149 & 0.611 & 4 \\
\hline 24 & RM280 & 4 & 55 & 155 & 0.675 & 4 \\
\hline 25 & RM297 & 1 & 55 & 148 & 0.525 & 3 \\
\hline 26 & RM307 & 4 & 55 & 174 & 0.654 & 4 \\
\hline 27 & RGNMS376 & 1 & 55 & 153 & 0.413 & 2 \\
\hline 28 & RM427 & 7 & 55 & 185 & 0.653 & 3 \\
\hline 29 & RM441 & 11 & 55 & 189 & 0.486 & 2 \\
\hline 30 & RM496 & 10 & 55 & 267 & 0.635 & 4 \\
\hline 31 & RM507 & 5 & 55 & 258 & 0.569 & 3 \\
\hline 32 & RM512 & 12 & 55 & 214 & 0.455 & 3 \\
\hline 33 & RM514 & 3 & 55 & 259 & 0.656 & 5 \\
\hline 34 & RM570 & 3 & 55 & 208 & 0.703 & 4 \\
\hline 35 & RM591 & 10 & 55 & 258 & 0.644 & 4 \\
\hline 36 & RM1108 & 10 & 55 & 124 & 0.642 & 4 \\
\hline 37 & RM1223 & 4 & 61 & 141 & 0.5 & 2 \\
\hline 41 & RM2197 & 12 & 55 & 160 & 0.441 & 5 \\
\hline 42 & RGNMS3062 & 9 & 55 & 168 & 0.559 & 3 \\
\hline 43 & RM3317 & 3 & 55 & 111 & 0.08 & 2 \\
\hline 44 & RM3353 & 6 & 50 & 116 & 0.497 & 2 \\
\hline 45 & RM3873 & 1 & 55 & 215 & 0.55 & 4 \\
\hline 46 & RM4455 & 10 & 55 & 116 & 0.703 & 5 \\
\hline 47 & RM4469 & 11 & 55 & 173 & 0.497 & 6 \\
\hline 48 & RM5512 & 2 & 55 & 106 & 0.219 & 2 \\
\hline 49 & RM5592 & 5 & 55 & 232 & 0.42 & 3 \\
\hline 50 & RM5814 & 6 & 55 & 105 & 0.611 & 3 \\
\hline 51 & RM5925 & 3 & 55 & 231 & 0.768 & 5 \\
\hline 52 & RM5994 & 5 & 61 & 105 & 0.288 & 3 \\
\hline 53 & RM6217 & 12 & 50 & 159 & 0.656 & 3 \\
\hline 54 & RM6759 & 3 & 55 & 324 & 0.278 & 2 \\
\hline 55 & RM7018 & 12 & 50 & 171 & 0.278 & 2 \\
\hline 56 & RM7170 & 11 & 55 & 177 & 0.444 & 2 \\
\hline 57 & RM7376 & 12 & 50 & 195 & 0.707 & 4 \\
\hline 58 & RM7446 & 6 & 55 & 188 & 0.566 & 4 \\
\hline 59 & RM8059 & 6 & 55 & 174 & 0.33 & 2 \\
\hline 60 & RM11865 & 1 & 55 & 146 & 0.219 & 2 \\
\hline 61 & HVSSR1227 & 9 & 55 & 346 & 0.469 & 2 \\
\hline 62 & RM13871 & 2 & 55 & 226 & 0.444 & 2 \\
\hline 63 & RM13911 & 2 & 55 & 91 & 0.542 & 3 \\
\hline 64 & RM16493 & 4 & 60 & 174 & 0.33 & 2 \\
\hline 65 & RM16657 & 4 & 60 & 361 & 0.351 & 3 \\
\hline 66 & RM16816 & 4 & 57 & 259 & 0.486 & 2 \\
\hline 67 & RM17469 & 4 & 55 & 394 & 0.73 & 5 \\
\hline 68 & RM21976 & 7 & 55 & 194 & 0.622 & 3 \\
\hline \multirow{2}{*}{\multicolumn{5}{|c|}{ Total }} & 0.153 & 2 \\
\hline & & & & & & 216 \\
\hline \multicolumn{5}{|r|}{ Mean } & 0.501 & 3.13 \\
\hline
\end{tabular}


Table.7 Distribution of 24 rice genotypes into different clusters based on SSR analysis

\begin{tabular}{|c|c|c|c|c|}
\hline S. No. & \multicolumn{2}{|c|}{ Cluster number } & Number of genotypes & Genotypes included \\
\hline \multirow[t]{2}{*}{1.} & \multirow[t]{2}{*}{ I } & $\mathrm{a}$ & 9 & $\begin{array}{l}\mathrm{CB} 16144, \mathrm{CB} 15138, \mathrm{CB} 16139, \mathrm{CB} \\
15120, \mathrm{CB} 12132, \mathrm{CB} 15127, \mathrm{CB} \\
16168, \mathrm{CB} 16166, \mathrm{CB} 16170\end{array}$ \\
\hline & & $b$ & 6 & $\begin{array}{l}\text { AC 38476, AC 38471, AC } 38479, \\
\text { Khao do ngoi, Paiyur 1, Palwan }\end{array}$ \\
\hline 2. & \multicolumn{2}{|c|}{ II } & 3 & Bluebonnet, Azucena, IR 64 \\
\hline 3. & \multicolumn{2}{|c|}{ III } & 3 & Nira, Pato, Iguapecateto \\
\hline 4. & \multicolumn{2}{|c|}{ IV } & 3 & CB 87R, CB 174R, CB 16174 \\
\hline
\end{tabular}

Fig.1 Dendrogram of 24 rice genotypes based on SSR marker data using UPGMA

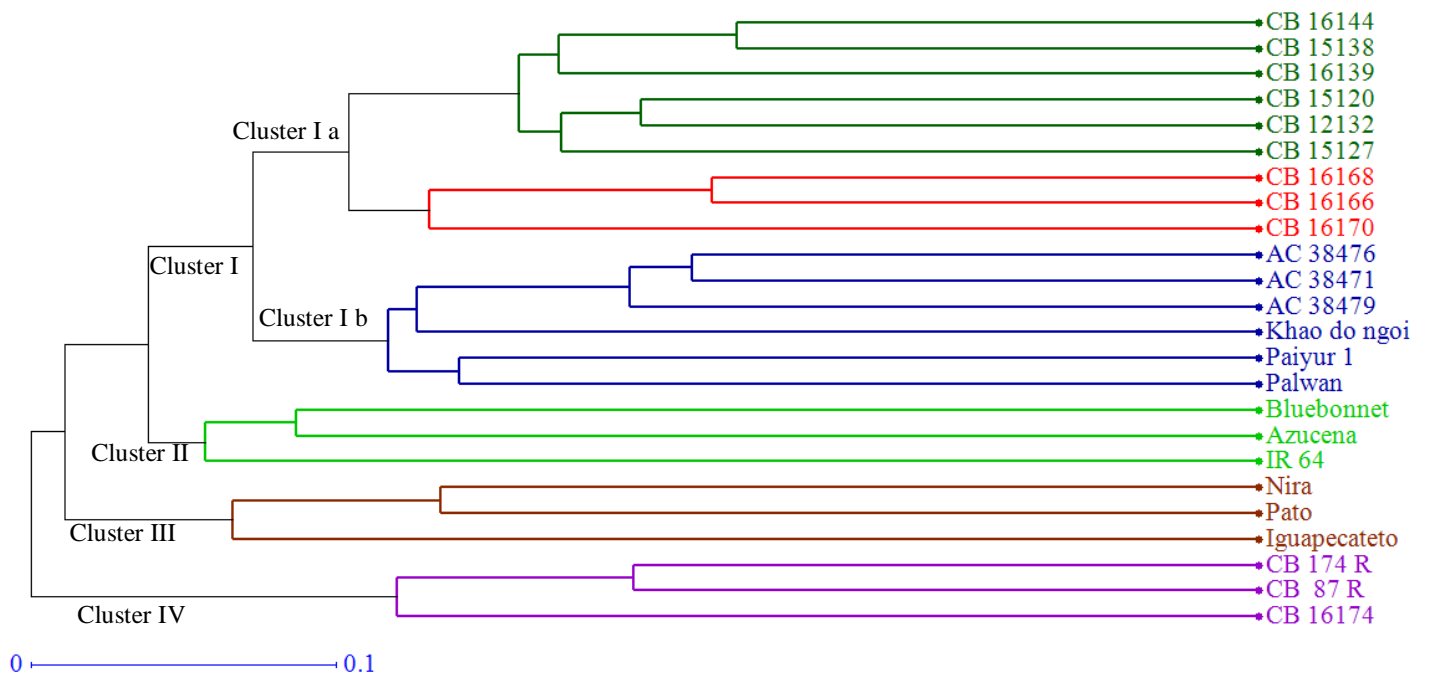

The highest mean values for panicle weight (3.94g) and spikelet fertility (85.24\%) were noted in cluster II. Genotypes with desirable plant height (mean $101.3 \mathrm{~cm}$ ) and relative earliness in flowering (mean 98.9 days) and high productive tillers (mean 16.77) are distributed in clusters III, $\mathrm{V}$ and IV respectively. Similar cluster means for single plant yield (V and I) and high kernel length (III and V) were observed. The cluster III recorded high mean values for kernel characters viz., length $(5.93 \mathrm{~mm})$, breadth $(2.6 \mathrm{~mm})$ and thickness $(1.79 \mathrm{~mm})$ and also 100 grain weight $(2.98 \mathrm{~g})$. Thus according to the breeding objectives, trait specific lines can be picked out from different clusters and involved in hybridization programs.

\section{Contribution of traits to genetic divergence}

The relative contribution of individual traits towards the divergence in the present material is given in Table 5. It could be easily deduced that the notable traits hover around kernel measurements and weight. Thus kernel L/B ratio $(35.14 \%), 100$ grain weight $(25.73 \%)$, kernel thickness $(14.13 \%)$ and kernel breadth (12.31\%) alone contribute for $87.31 \%$ of the total genetic divergence. These findings confirm our speculations as tropical japonica lines are also involved. The other yield contributing traits were panicle length (3.62\%), spikelet fertility $(2.90 \%)$ and panicle weight $(2.54 \%)$. Single plant yield contributed for $2.18 \%$. In the present materials, flowering 
plant height, productive tillers and secondary branches panicle ${ }^{-1}$ had nil role in divergence.

Though the results obtained are contradictory to many other similar studies, few investigations report divergence for kernel traits. In a previous study Haque et al., (2014) described kernel length as maximum contributing trait towards divergence (34.32\%). Vennila et al., (2011) claimed that grain length $(14.51 \%)$ followed by grain breadth $(10.49 \%)$ were among the top three contributing characters for divergence. Test weight as the major contributing trait for divergence $(30.76 \%$ and $43.32 \%)$ were published by Chandramohan et al., (2016) and Guru et al., (2017) respectively. Selection of the parents depends on the per cent contribution of the trait towards divergence (Nayak et al., 2004). It can be concluded that while choosing parents for hybridization and selection in the further generations from the above set of lines, kernel traits should be considered to get the desired results.

\section{Molecular genetic diversity}

The analysis using Simple Sequence Repeat markers provides an accurate and unbiased assessment and reveals detailed information on the genetic diversity of genotypes. In the present study, out of 114 SSR markers used in the diversity analysis, 69 were observed to be polymorphic. In total, 216 alleles were detected in 69 polymorphic primers. The number of alleles amplified ranged between two to seven (Table 6). The average number of alleles obtained was 3.13 which is similar to the findings of Hee Chung et al., (2007) (3 alleles); Sajib et al., (2012) (3.3 alleles) and Ahmed et al., (2015) (3.24 alleles) but the average number of allele is contrastingly low when compared to the result of Brondani et al., (2006) (14.6 alleles). Choudhary et al., (2013) reported the average number of alleles to be 3.6 and the number of alleles ranged from three to seven which is very much similar to the outcome of present investigation.

The high number of alleles detected may be due to the broader genetic base of the genotypes. The closely related genotypes usually exhibit low number of alleles. The Polymorphism Information Content (PIC) which reflects the allelic diversity varied from 0.08 (RM2) to 0.81 (RM3317) and the average Polymorphic Information Content was 0.5 . Similar study was made by Thomson et al., (2007) who reported average polymorphism information content value of 0.66; Sajib et al., (2012) observed average PIC to be 0.48 that ranged between 0.14 (RM510) and 0.71 (RM163); Singh et al., (2015) reported PIC range as 0.267 (RM 316) to 0.654 (RM 481) withan average of 0.47 and Babu et al., (2014) summarized that it varied from 0.02 to 0.77 , with an average of 0.50 .

The dendrogram based on the UPGMA classified the 24 genotypes into four major distinguishable clusters (Table 7). Cluster I being the biggest had two sub-clusters with sub-cluster Ia having nine indica genotypes and sub-cluster $\mathrm{Ib}$ having five tropical japonica and one indica genotype Paiyur 1.In cluster II, IR 64 clubbed with tropical japonicas viz., Azucena and Blue Bonnet. The cluster III was formed with Nira, Pato and Iguapecateto, all belonging to tropical japonica, while cluster IV had all indica types CB 87R, CB 174R and CB 16174 (Fig. 1).

Comparing diversity for phenotypically expressed agronomic traits using $\mathrm{D}^{2}$ statistics and at molecular level using SSR markers, it could be well established that all indica and all tropical japonica did not form separate clusters. There was intermingling of genotypes from different sub species into one cluster. Some distinct genotypes in each 
group were accommodated in the same cluster. Two common observations are that tropical japonica genotypes Nira, Pato, Iguapecateto were placed together in one cluster (cluster IV and III in the former and latter method) and Azucena and Bluebonnet (cluster IV and II) in another cluster in both the types of analysis. Similarly the indica genotypes IR 64, Paiyur 1 and CB 16174 fell in separate clusters by both methods. Contradictions are that three indica genotypes viz., CB 16166, CB 16168 and CB 16170 derived from same cross ADT 49/Wag wag placed at different clusters in former analysis were grouped in the same cluster in marker analysis.

The Jaccard's dissimilarity index determines the degree of relatedness between the genotypes. Genotypes showing Jaccard's dissimilarity coefficient value closer to 1 specifies maximum dissimilarity and the values closer to ' 0 ' denotes maximum similarity. The Jaccard's dissimilarity index was lowest (0.34) between CB 16144 and CB 15138.The highest (0.89) value was recorded between CB 16174 and Pato as well as between $\mathrm{CB} 16174$ and $\mathrm{AC}$ 38476. This implies that CB 16174 (ADT 49/JGL 384) is highly diverse from Pato and AC38476 whereas, CB 16144 (IR 20/JGL 384) and CB 15138 (CB 09153/BG 358) are closely related genotypes though they do not share a common pedigree.

Indica genotypes are exhibiting broader genetic base than the japonica genotypes that shows indica are more diverse that japonica which concede to the report of Zhang et al., (1992). Therefore crosses can be planned by utilising these diverse genotypes between indica and tropical japonica or between indicas for bringing together the complementary interaction of gene constellations of diverse nature and broaden the genetic base to develop new cultivars.

\section{References}

Ahmed, MS, S Parveen, MK Bashar, and AKM Shamsuddin. 2015. "Genetic divergence of Balam rice (Oryza sativa L.) germplasm of Bangladesh." Bangladesh Rice Journal 19 (1):9-15.

Babu, B Kalyana, Vimla Meena, Vasudha Agarwal, and PK Agrawal. 2014. "Population structure and genetic diversity analysis of Indian and exotic rice (Oryza sativa L.) accessions using SSR markers." Molecular biology reports 41 (7):4329-4339.

Baradhan, G, and P Thangavel. 2011. "D2 analysis in rice (Oryza sativa L.)." Plant Archives 11 (1):373-375.

Beevi, H Apsath, and M Venkatesan. 2015. "Genetic divergence studies in rice (Oryza sativa L.) genotypes under natural saline condition." Journal of the Andaman Science Association 20(1): 35-38.

Bomit L., et al., (2018) Evaluation of Rice (Oryza sativa L.) Genotypes based on Agro-Morphological Traits and Genetic Diversity. International Journal of Agriculture Sciences, 10(22): 74937497.

Brondani, Claudio, Tereza Cristina Oliveira Borba, Paulo Hideo Nakano Rangel, and Rosana Pereira Vianello Brondani. 2006. "Determination of genetic variability of traditional varieties of Brazilian rice using microsatellite markers." Genetics and Molecular Biology 29 (4): 676-684.

Chakma, SP, H Huq, F Mahmud, and A Husna. 2012. "Genetic diversity analysis in rice (Oryza sativa L.)." Bangladesh Journal of Plant Breeding and Genetics 25(1): 31-39.

Chandramohan, Y, B Srinivas, S Thippeswamy, and D Padmaja. 2016. "Diversity and variability analysis for yield parameters in rice (Oryza sativa 
L.) genotypes." Indian Journal of Agricultural Research 50 (6).

Choudhary, Gangaprasad, Nagireddy Ranjitkumar, Malathi Surapaneni, Dondapati Annekitty Deborah, Abhilash Vipparla, Ghanta Anuradha, Ebrahimali Abubacker Siddiq, and Lakshminarayana Reddy Vemireddy. 2013. "Molecular genetic diversity of major Indian rice cultivars over decadal periods." PloS one 8(6): e66197.

Guru, Tulasi, V Padma, DVV Reddy, PR Rao, D Sanjeeva Rao, T Ramesh, and KV Radhakrishna. 2017. "Genetic diversity analysis for yield attributing traits in rice genotypes." Research on Crops 18(2): 311-315.

Haque, Shafina, SK Pradhan, and ON Singh. 2014. "Genetic diversity analysis of direct seeded rice genotypes under drought situation." ORYZA-An International Journal on Rice 51 (2):121-124.

Hee Chung, JI, KIM Young Il, LEE Hee Bong, CHO Jin-Woong, SEO Sung, and Takeo Yamakawa. 2007. "Genetic diversity of colored rice lines based on botanical characteristics and simple sequence repeat (SSR) markers." J. Fac. Agr., Kyushu Univ 52 (2):287-293.

Kumar, Nitesh, PK Singh, A Vaishampayan, Rajesh Saini, Mukh Ram, Aparajita Singh, and NK Singh. 2014. "Genetic divergence analysis in rice under irrigated conditions." Indian J. Plant Genet. Resour 27 (3):246-250.

Mahalanobis, PC. 1928. "Statistical study of the Chinese head."

Nayak, AR, D Chaudhury, and JN Reddy. 2004. "Genetic divergence in scented rice." Oryza 41 (3\&4):79-82.

Ndjiondjop, Marie Noelle, Fousseyni Cisse, Gezahegn Girma, Mounirou Sow, Roland Bocco, Gustave Djedatin, and Fatondji Blandine. 2010. "Morphoagronomic and molecular characterisation of Oryza glaberrima germplasm from Mali." African Journal of Biotechnology 9 (44):7409-7417.

Ovung, Chanbeni Y, GM Lal, and Prashant Kumar Rai. 2012. "Studies on genetic diversity in rice (Oryza sativa L.)." Journal of Agricultural Technology 8(3): 1059-1065.

Palaniraja, K, and Y Anbuselvam. 2010. "D 2 ANALYSIS IN RICE (Oryza sativa L.)." Agricultural Science Digest 30 (3).

Radhakrishna Rao, C. 1952. Advanced statistical methods in biometric research: A Division Of Macmillan Publishing Co, Inc New York; CollierMacmillan.

Ranjith, P, S Sahu, SK Dash, DN Bastia, and BD Pradhan. 2018. "Genetic diversity studies in rice (Oryza sativa L.)." Journal of Pharmacognosy and Phytochemistry 7(2): 2529-2531.

Sajib, Abdul M, Md Hossain, ATMJ Mosnaz, Hosneara Hossain, Md Islam, Md Ali, and Shamsul H Prodhan. 2012. "SSR marker-based molecular characterization and genetic diversity analysis of aromatic landreces of rice (Oryza sativa L.)." Journal of BioScience \& Biotechnology 1 (2).

Shanmugam, AS, and SR Sree Rangasamy. 1982. Genetic diversity for quantitative characters in green gram (Vigna radiata (L.) Wilczek).

Shanmugasundaram, P, J Souframanien, and S Sadasivam. 2000. "Genetic divergence among rice varieties released from paddy breeding station, Coimbatore, India." Oryza 37 (3):225227.

Siddique, MA, M Khalequzzaman, MZ Islam, MS Ahamed, and ESMH Rashid. 2013. "Genetic diversity in local Boro rice (Oryza Sativa L.) genotypes of Bangladesh." Bangladesh Journal of Plant Breeding and Genetics 26 (1):1924. 
Singh, Anand, Anushka Singh, and PK Singh. 2018. "Evaluation of genetic divergence existing in the rice germplasm collections." Evaluation 3 (6).

Singh, Aparajita, R Saini, Jyoti Singh, M Arya, Mukh Ram, Mukul Singh, and PK Singh. 2015. "Genetic diversity studies in rice (Oryza Sativa L.) using microsatellite markers." International Journal of Agriculture, Environment and Biotechnology 8 (1):143.

Smith, JSC, ECL Chin, H1 Shu, OS Smith, SJ Wall, ML Senior, SE Mitchell, S Kresovich, and J Ziegle. 1997. "An evaluation of the utility of SSR loci as molecular markers in maize (Zea mays L.): comparisons with data from RFLPs and pedigree." Theoretical and Applied Genetics 95 (1-2):163-173.

Thomson, Michael J, Endang M Septiningsih, Fatimah Suwardjo, Tri J Santoso, Tiur S
Silitonga, and Susan R McCOUCH. 2007. "Genetic diversity analysis of traditional and improved Indonesian rice (Oryza sativa L.) germplasm using microsatellite markers." Theoretical and Applied Genetics 114 (3):559-568.

Tiruneh, Altaye, Wosene Gebrselassie, and Abush Tesfaye. 2019. "Genetic Diversity Study on Upland Rice (Oryza sativa L.) Genotypes Based on Morphological Traits in Southwestern Ethiopia." Asian Journal of Crop Science 11 (1):17-24.

Zhang, Qifa, MA Saghai Maroof, T Yj Lu, and BZ Shen. 1992. "Genetic diversity and differentiation of indica and japonica rice detected by RFLP analysis." Theoretical and Applied Genetics 83 (4):495-499.

\section{How to cite this article:}

Sangeetha, R., R. Saraswathi, K. Amudha and Senthil Kumar, G. 2019. Genetic Divergence Studies in Subspecies of Oryza sativa L. Int.J.Curr.Microbiol.App.Sci. 8(07): 834-845. doi: https://doi.org/10.20546/ijcmas.2019.807.100 